\title{
Management of aortic arch hypoplasia in neonate and infants
}

\author{
Mehmet Onalan ${ }^{1}$, Bahar Temur ${ }^{2}$, Selim Aydin ${ }^{2}$, Serdar Basgoze $^{2}$, Fusun Güzelmeriç ${ }^{2}$, \\ Ender Odemis ${ }^{2}$, and Ersin Erek $^{2}$ \\ ${ }^{1}$ Acibadem University \\ ${ }^{2}$ Acibadem Universitesi Tip Fakultesi
}

October 5, 2020

\begin{abstract}
Objectives:Surgical management of aortic arch hypoplasia with associated intra-cardiac anomalies is a challenge in newborns. We reviewed the characteristics and outcomes of neonates and infants who underwent pulmonary artery banding concomitant to arch repair and single-stage total repair at our institution. Methods:Medical records of 60 patients undergoing aortic arch reconstruction for aortic arch hypoplasia between 2014 to 2019 were retrospectively reviewed.Twenty-five patients were female $(41.6 \%)$, and the age of the patients ranged from 4 to 120 days (median 19.5 days). The patients were divided into two groups; Group 1 (23 patients) underwent pulmonary artery banding concomitant to arch repair, Group 2 (37 patients) underwent single-stage total repair in addition to arch repair. All arch repair procedures consisted of an extended (to the midportion of the ascending aorta)patch aortoplasty. Results:Postoperative early mortality occurred in 12 patients, 8 in Group 1(34.8\%), and 4 in Group $2(10.8 \%)$. There was an early survival advantage in group $2(\mathrm{p}=0.019)$. Recoarctation was occurred in 13 cases $(21.6 \%)$, and $11(18.3 \%)$ of them required reintervention (balloon angioplasty:7, re-operation:4). On univariate analysis, risk factors associated with death were pulmonary artery banding (HR,0.44;CI,0.09-2;p=0.019),prematurity (HR,4,67;CI,1.34$16.18 ; \mathrm{p}=<0.001)$, preoperative mechanical ventilation support requirement (HR,0.048;CI, 0.52-6.39; $\mathrm{p}=0.048)$, and functional single ventricle $(\mathrm{HR}, 0.43 ; \mathrm{CI}, 0.1-1.86 ; \mathrm{p}=0.006)$. The mean duration of follow-up was $21.9 \pm 15.1 \mathrm{months}$, and there was no late death in each group. Conclusion:Single-stage repair of aortic arch hypoplasia with intracardiac pathologies has better results than palliation, according to survival rates and postoperative results. The use of patch augmentation technique in aortic arch hypoplasia is valid and associated with an acceptable incidence of recurrent arch obstruction.
\end{abstract}

\section{Management of aortic arch hypoplasia in neonate and infants}

Original Article

Short Title: Aortic arch hypoplasia surgery

Mehmet Akif Onalan ${ }^{1}$ M.D., Bahar Temur ${ }^{1}$ M.D., Selim Aydın ${ }^{1}$ M.D., Serdar Basgoze ${ }^{1}$ M.D., Fusun Guzelmeric $^{2}$ M.D., Ender Odemis ${ }^{3}$ M.D., Ersin $\operatorname{Erek}^{1}$ M.D

The institution where the research was done:

Acıbadem University Faculty of Medicine, Atakent Hospital, İstanbul, Turkey

Author Affiliations:

${ }^{1}$ Department of Cardiovascular Surgery, Acibadem Mehmet Ali Aydinlar University Faculty of Medicine, Atakent Hospital, İstanbul, Turkey

${ }^{2}$ Department of Anesthesiology, Acibadem Mehmet Ali Aydinlar University Faculty of Medicine, Atakent Hospital, İstanbul, Turkey 
${ }^{3}$ Department of Pediatric Cardiology, Acibadem Mehmet Ali Aydinlar University Faculty of Medicine, Atakent Hospital, İstanbul, Turkey

\section{Correspondence:}

Mehmet Akif Onalan M.D., Acibadem Mehmet Ali Aydinlar University Faculty of Medicine, Atakent Hospital, Department of Cardiovascular Surgery, 34303 Halkall, İstanbul, Turkey.

Tel: +90212 - 4044731

e-mail: mehmetakifonalan@gmail.com

Fax: +90 212-404 4797

Objectives: Surgical management of aortic arch hypoplasia with associated intra-cardiac anomalies is a challenge in newborns. We reviewed the characteristics and outcomes of neonates and infants who underwent pulmonary artery banding concomitant to arch repair and single-stage total repair at our institution.

Methods: Medical records of 60 patients undergoing aortic arch reconstruction for aortic arch hypoplasia between 2014 to 2019 were retrospectively reviewed.Twenty-five patients were female (41.6\%), and the age of the patients ranged from 4 to 120 days (median 19.5 days).The patients were divided into two groups;Group 1 (23 patients) underwent pulmonary artery banding concomitant to arch repair, Group 2 (37 patients) underwent single-stage total repair in addition to arch repair.All arch repair procedures consisted of an extended (to the midportion of the ascending aorta)patch aortoplasty.

Results: Postoperative early mortality occurred in 12 patients, 8 in Group $1(34.8 \%)$, and 4 in Group $2(10.8 \%)$. There was an early survival advantage in group $2(\mathrm{p}=0.019)$. Recoarctation was occurred in 13 cases $(21.6 \%)$, and 11 (18.3\%) of them required reintervention (balloon angioplasty:7, reoperation:4).On univariate analysis, risk factors associated with death were pulmonary artery banding (HR,0.44;CI,0.09-2; $\mathrm{p}=0.019$ ), prematurity ( $\mathrm{HR}, 4,67 ; \mathrm{CI}, 1.34-16.18 ; \mathrm{p}=<0.001)$, preoperative mechanical ventilation support requirement (HR, $0.048 ; \mathrm{CI}, 0.52-6.39 ; \mathrm{p}=0.048$ ), and functional single ventricle (HR, $0.43 ; \mathrm{CI}, 0.1$ $1.86 ; \mathrm{p}=0.006)$. The mean duration of follow-up was $21.9 \pm 15.1$ months, and there was no late death in each group.

Conclusion: Single-stage repair of aortic arch hypoplasia with intracardiac pathologies has better results than palliation, according to survival rates and postoperative results. The use of patch augmentation technique in aortic arch hypoplasia is valid and associated with an acceptable incidence of recurrent arch obstruction.

Keywords: Congenital heart disease; hypoplastic aortic arch; aortic arch plasty

\section{Introduction}

Aortic arch hypoplasia (AAH) involving all segments of the arch, usually occurs in neonate and infants with intra-cardiac anomalies ${ }^{1-3}$. Discrete aortic coarctation is rare in infantile period, and up to $31 \%$ of these patients have associated with some degree of aortic arch hypoplasia (AAH) ${ }^{1}$. Although there are still no definite diagnostic criteria, AAH is generally considered present, when the aortic arch diameter between the innominate artery and the left common carotid artery is $<60 \%$, between the left common carotid artery and the left subclavian artery is $<50 \%$, and the aortic isthmus is $<40 \%$ of the ascending aorta diameter ${ }^{1}$. Surgical management of aortic arch hypoplasia is a surgical challenge. Associated intra-cardiac pathologies are present with varying severity ranging from a simple ventricular septal defect to hypoplastic left heart syndrome, that may affect the decision making and outcomes. There are also great diversity in the surgical repair techniques myocardial, and cerebral protection strategies. Moreover, postoperative recurrent aortic arch obstruction remains a significant problem in mid-to long term ${ }^{3,4}$.

Decision making between single stage repair or staged approach is not only depend on the intracardiac anomaly, but also patients' general condition and surgeons' preference. In the current study, we reviewed our early and mid-term results in neonates and infants with aortic arch hypoplasia and intracardiac anomalies in terms of single stage or staged repair. 


\section{Materials and methods}

Medical records of 60 consecutive patients who underwent aortic arch reconstruction between January 2014 and December 2019 were retrospectively reviewed. Patients with hypoplastic left heart syndrome, interrupted aortic arch, and isolated coarctation were excluded from the study. All patients but 3 had associated intracardiac anomaly. Our study received ATADEK-2020/2 (numbered 2020-2/6) Ethics Committee approval on $11 / 02 / 2020$. We defined aortic arch hypoplasia according to the above mentioned criteria ${ }^{1}$. Transthoracic echocardiography was used for the diagnosis of all patients. Their aortic arch anatomy were examined in detail. Computerized tomography angiography was performed upon any suspicion on the echocardiographic diagnosis. The mean diameter of proximal transvers arch (between the innominate and the left carotid arteries) was $3.61 \pm 0.9 \mathrm{~mm}$ (the mean $\mathrm{Z}$ score: $-5.21 \pm-1.44$ ), distal transvers arch (between the left carotid and the left subclavian arteries) was $3.6 \pm 0.91 \mathrm{~mm}$ (the mean $\mathrm{Z}$ score: $-3.24 \pm-1.38$ ), and the isthmic arch (between the left subclavian and the ductus arteriosus) was $2.98 \pm 0.93 \mathrm{~mm}$ (the mean $\mathrm{Z}$ score: $-3.98 \pm$ $-1.65)$.

The age of the patients ranged from 4 to 120 days (median 19.5 days), their weight ranged from 2 to $5.3 \mathrm{~kg}$ (mean, $3.2 \pm 0.73 \mathrm{~kg}$ ), and their body surface area (BSA) ranged from 0.16 to $0.28 \mathrm{~m}^{2}$ (mean, $0.21 \pm 0.02$ $\left.\mathrm{m}^{2}\right)$. Fourty-six patients $(76.6 \%)$ were neonates, and 11 patients were prematures (18.3\%). Male to female ratio was $35 / 25(58.4 \% / 41.6 \%)$.

The patients were divided into two groups: Group 1 consisted of 23 patients who underwent palliation with pulmonary artery banding concomitant to aortic arch repair. Group 2 consisted of 37 patients who underwent single-stage total repair. The main characteristics, associated intracardiac anomalies, operative details, and perfusion strategies for both groups are described in table 1 and 2 .

Ductal dependency and prostaglandin E1 infusion were necessary in 45 patients (75\%), and forty-two patients $(70 \%)$ had congestive heart failure preoperatively. Sixteen patients $(26.6 \%)$ were required mechanical ventilatory support before the operation. Three patients had trisomy 21, and 3 had Williams syndrome. Twelve patients $(20 \%)$ had poor preoperative clinical conditions. Five of them were treated for sepsis, 4 had congenital pneumonia, 2 had acute renal failure, and the last one had multiorgan failure. Three patients had undergone surgery due to esophageal atresia $(\mathrm{n}=2)$ and anal atresia $(\mathrm{n}=1)$ before cardiac operations.

\section{Surgical repair technique}

Median sternotomy and cardiopulmonary bypass $(\mathrm{CPB})$ was performed to all patients. The thymus was totally excised and the pericardium was harvested. Straight tip $8 \mathrm{Fr}(2.7 \mathrm{~mm})$ arterial cannula (RMI, Edwards Lifesciences LLC, Irvine, CA) was inserted into the distal ascending aorta and advanced into the innominate artery for antegrade selective cerebral perfusion (ASCP) during the aortic arch repair. No additional ductal aortic cannulation was performed. Distal perfusion was maintained through the arterial duct by snaring both pulmonary artery branches and keeping the heart filled during cooling. Near-infrared spectroscopy (NIRS) monitoring was performed. Usually, it took about 10-15 minutes to reach the desired core temperature. The Alfa-stat strategy was used in acid-base management for cerebral protection. Aortic arch repair was performed first in all patients. Aortic arch vessels, duct and descending aorta were dissected free. During moderate hypothermia $\left(26^{\circ} \mathrm{C}\right)$, aortic clamp was inserted between the innominate and left carotic artery to maintain selective cerebral and coronary flow. The flow rate was adjusted at about $50 \mathrm{ml} / \mathrm{kg}$ per min. The mean blood pressure of the right radial artery was sustained at about $40-50 \mathrm{mmHg}$, and the mean hematocrit level was sustained at around $30 \%$. Yasargil neurovascular clips were used to close the left carotid and left subclavian arteries. The descending aorta was clamped as far distally as possible with a side clamp. Arterial duct was ligated and resected from the aortic end. The aortic arch was incised until proximal aortic clamp. After all ductal tissue was resected, distal descending aorta was anastomosed to the aortic arch to form a native posterior wall. Distal descending aorta was incised anteriorly and a pericardial patch was sutured to augment the anterior wall of the aortic arch. When the suture line approaches to the aortic clamp, innominate artery was snared over the aortic cannula and ASCP was commenced. At the same time, tepid blood cardioplegia was given. Aortic clamp was moved to the proximal ascending aorta and arch incision 
was extended to the midportion of the ascending aorta. Remaining of the pericardial patch was sutured to cover the rest of the aortic incision. After de-airing of the aorta, clamps were removed, aortic cannula moved into the aortic arch and whole body perfusion was started. During rewarming pulmonary artery banding or intracardiac repairs were performed.

\section{Statistical Analysis}

Statistical analyses were performed by a biostatistician using SPSS Statistics version 21.0 (IBM). The normality of data analyzed by using Kolmogorov-Smirnov. The descriptive statistics were reported as mean \pm standart deviation, medians, and ranges (min-max). Independent Sample T-Test and Mann Whitney U test, these tests are used to see there or not the average difference between the two independent groups, accordingly in parametric and nonparametric variables. The relationship between two sets of data was analyzed by Spearman's rank correlation test. OS analyses of the groups were evaluated with Kaplan-Meier curves, and differences were tested with a log-rank test. All comparative tests were 2-tailed, and a p -value of less than 0.05 was considered to be statistically significant. Effects of covariates on possibility of survivals in univariate analysis are reported as hazard ratio (HR) with $95 \%$ confidence interval (CI).

\section{Results}

Operative and postoperative results are listed in table 2. Mean BSA of the patients in group 1 was lower than group $2(\mathrm{p}=0.044)$, and the number of the premature patients was higher in group $1(\mathrm{p}=0.056)$. In group 1, 4 patients underwent atrial septectomy, and 2 underwent aortic valve commissurotomy because of bicuspid aortic valve, additionally. Pulmonary artery banding was performed to one of these two patients who underwent aortic valve commissurotomy due to multiple VSD. In group 2, 18 patients underwent VSD closure; 12 patients underwent arterial switch operation (ASO) with VSD closure; one underwent aortopulmonary window repair. Although 3 of the remaining 6 patients had a bicuspid aortic valve, the valve did not need commissurotomy, and just like 3 patients with isolated arch hypoplasia, these patients underwent isolated aortic arch repair. The mean ASCP times were $22.4 \pm 7.4$ min. The mean CPB and aortic crossclamping (CC) times were significantly longer in group 2 (CPB time: $56.9 \pm 10.4 \mathrm{~min}$ in group 1 versus $108.7 \pm 50.5 \mathrm{~min}$ in group $2, \mathrm{p}<0.001$; CC time: $12.6 \pm 6.5 \mathrm{~min}$ in group 1 versus $54.4 \pm 36$ min in group $2, \mathrm{p}<0.001)$.

In group 1, 10 patients underwent pulmonary artery banding despite having functional biventricle and VSD. Of these 10 patients, 4 (40\%) were premature, $6(60 \%)$ had low body weight ([?] $2.5 \mathrm{~kg})$, and $3(30 \%)$ had poor preoperative condition or required mechanical ventilation support. Only 3 patients did not have any comorbidities and VSDs closing were postponed to second stage due to anatomical location or size. They had large subaortic, apical musculer and large inlet-outlet lying VSDs, respectively.

Hospital mortality were $34.8 \%$ and $10.8 \%$ respectively (8/23 in group 1 and $4 / 37$ in group $2, \mathrm{p}=0.024)$. Of the 8 patients in group 1, $6(75 \%)$ were neonate, $4(50 \%)$ were male, $4(50 \%)$ had low body weight $(<2.5 \mathrm{~kg}), 5(62.5 \%)$ had functional single ventricle, and $5(62.5 \%)$ had preoperative poor condition or required mechanical ventilation support. Bleeding complication was occurred in 2 patients, low cardiac output was occurred in 3 patients, and they died due to sepsis in the postoperative course. One patient had sudden cardiac arrest on the postoperative day 2 and died despite resuscitation. Extracorporeal membrane oxygenation (ECMO) support did not use in this patient because of low body weight and poor preoperative condition. The remaining 2 patients died due to Klebsiella pneumoniae sepsis and Enterococcus faecium mediastinitis after the long postoperative course, respectively. Of the 4 patients in group 2, all patients were neonate and male, $1(25 \%)$ had low body weight $(<2.5 \mathrm{~kg})$, and $3(75 \%)$ needed preoperative sepsis treatment or required mechanical ventilation support. One patient underwent reoperation due to mitral valve insufficiency after the perimembranous VSD closure, this patient and another patient died because of sepsis after long postoperative course. ECMO support was used in the remaining 2 patients due to low cardiac output. One of them weaned from ECMO but could not survive and died due to multi organ failure, the another one died on ECMO because of Klebsiella pneumoniae sepsis.

The median duration of intensive care unit (ICU) and hospital stay were 11 days (range 2-228), and 19 days 
(range 2-230), respectively. Although the median length of ICU stay was not statistically significant, was longer in group 1 ( 15 days to 10 days, $\mathrm{p}=0.45$ ). In addition, the median length of hospital stay was not different between two groups (19 days to 19 days, $\mathrm{p}=0.93)$. Sternal closure was delayed in 35 cases $(58,3 \%)$ by a mean of $4.3+-5.9$ days (range 1 to 33 ), and there was no statistically significant difference between two groups ( $12 / 23$ in group 1 and $23 / 37$ in group $2, \mathrm{p}=0.44)$. However, the mean duration of delayed sternal closure time was significantly higher in group $1(6.8+-8.7$ versus $2.7+-2.1, \mathrm{p}=0.044)$. Twenty-three patients $(39.6 \%)(10 / 23$ versus $13 / 37, \mathrm{p}=0.48)$ needed a long duration of mechanical ventilation ( $>7$ days), and twenty-four patients needed prolonged ICU stay ( $>15$ days) $(12 / 23$ versus $11 / 37, \mathrm{p}=0.12)$. VAC therapy was performed due to mediastinitis or delayed sternal closure in 5 cases $(8.3 \%)$, and was significantly higher in group $1(4 / 23$ versus $1 / 37, \mathrm{p}=0.045)$. Three patients $(5 \%)$ needed re-exploration for bleeding, and two patients (3.3\%) experienced supraventricular dysrhythmias. Eight patients (13.3\%) showed postoperative low cardiac output syndrome, and that was statistically significantly higher in group 1 (6/23 versus $2 / 37$, $\mathrm{p}=0.022)$. Sudden cardiac arrest was occurred in 4 cases $(6.6 \%)$, and all of them were in group $1(\mathrm{p}=0.009)$. Two patients needed postoperative ECMO support due to extracorporeal cardiopulmonary resuscitation or low cardiac output. Unfortunately, although one patient weaned from ECMO, both patients died due to sepsis. Tracheostomy was required due to the long duration of mechanical ventilation in four cases $(6.6 \%)$. Sepsis was occurred in 7 cases $(11.6 \%)(5 / 23$ versus $2 / 37, \mathrm{p}=0.055)$, and one of them had chylothorax. Two patients underwent left diaphragm plication operation because of left diaphragm paralysis in the early postoperative period. Peritoneal dialysis was required in 3 cases (5\%) because of renal insufficiency and/or positive fluid balance. Minor neurological events occurred in 3 cases (5\%). Three patients (5\%) were needed antihypertensive therapy while discharged from the hospital. Outcomes and complications were presented in Table 3.

Follow-up was completed for 93,75\% (45/48) survivors with a mean duration of $21.9+-15.1$ months (range 2 to 58 months). Kaplan-Meier survival for both groups is shown in Figure 2, and there was an early survival advantage in group $2(\mathrm{p}=0.019)$. Risk factors affecting survival are listed in Table 4 . No mortality was observed during follow-up period.

Recoarctation was occurred in 13 cases (27\%) and 11 (22.9\%) of them required reintervention (Figure 3). We used glutaraldehyde treated autologous pericardium in 21 patients, bovine pericardium in 19 patients, porcine pericardium in 20 patients, and there was no statistically significant relationship between patch types and recoarctation $(\mathrm{p}=0,77)$. Moreover, there was no association between $\mathrm{Z}$ scores of the proximal aortic arch, distal aortic arch, transverse aortic arch, and recoarctation. Similarly, the incidence of reintervention was not statistically significant between the two groups $(\mathrm{p}=0,89)$ (Figure 4$)$. Among 13 patients, 7 patients underwent balloon dilation angioplasty, 4 patients required reoperation as patch aortoplasty after unsuccessful balloon dilatation, and the last 2 patients were closely followed up by medical treatment. The mean of arch reintervention time was $8.7+-7.3$ months (range 2 to 27 months), and the angioplasty evaluation of the mean gradient $38.5+-15.5 \mathrm{~mm} \mathrm{Hg}$ dropped to the mean of $6.1+-4.5 \mathrm{mmHg}$ gradient by balloon angioplasty. One case required stent implantation (9x17 mm stent; Visi-pro, Medtronic, USA) to the descending aorta after surgical reintervention. There were no cases of bronchial compression or aneurysm of the aortic arch. Patients required reinterventions were presented in table 5.

Of the remaining 15 patients $(65.2 \%)$ in group 1 , two were lost to follow-up. Two patients underwent pulmonary debanding with VSD closure. Two underwent transcatheter pulmonary debanding, and remaining small muscular VSDs were following-up. One patient underwent Yasui procedure, one underwent Glenn with Damus-Kaye-Stansel anastomosis, one underwent pulmonary debanding with AVSD repair. All patients were survived after the second stage operation, and were in good clinical condition. The remaining six patients were under follow-up for the second stage operation.

\section{Discussion}

The surgical management of aortic arch hypoplasia with associated intracardiac anomalies is a challenge in neonates and infants. According to intracardiac anomalies, palliation or total repair in addition to arch repair is controversial. Moreover, significant proximal transverse aortic arch obstruction is rare than the 
distal arch and isthmus hypoplasia, but almost always requires a surgical approach via a sternotomy ${ }^{1}$. In our cohort, all patients had tubular arch hypoplasia, so we performed all arch reconstructions via sternotomy and enlarged the aortic patches to the midportion of the ascending aorta. We attempted to perform total intracardiac repair in all biventricle patients, but in single ventricle patients and biventricle patients with preoperative comorbidities we performed pulmonary artery banding. From this point of view, BSA values during surgery were significantly lower in the palliation group and the number of patients weighing $<2.5 \mathrm{~kg}$ was higher.

Several techniques and patch types have been proposed through the years for repair of aortic arch obstructions, and recurrent obstruction in the correspondence of the aortic arch surgery, is the most frequently reported complication, with a hugely variable incidence reported from 2 to $38 \%^{5-7}$. Roussin and colleagues presented that aortic arch repair associated with pulmonary autograft patch augmentation resulted in superior midterm outcomes, thus reducing the risk of recorctation and tracheobronchial compression in comparison to patch aortoplasty with homograft and pericardial patch augmentation ${ }^{8}$.Morales and colleagues presented excellent results with $100 \%$ freedom from arch reintervention during a 5 -year follow-up in neonates with interrupted aortic arch using aortic arch advancement technique ${ }^{9}$. On the other hand, Gaynor and colleagues published no difference regarding the incidence of reintervention by patch reconstruction of the $\operatorname{arch}(20 \%)$ or resection with end-to-end anastomosis $(25 \%)^{10}$. In our technique, distal descending aorta was anastomosed to the aortic arch to form a native posterior wall, and patch augmentation was extended to the midportion of the ascending aorta. In our opinion, it is safer not to use too long and wide patches, and to extend the patch like us. We preferred glutaraldehyde treated autologous pericardium in 21 patients, bovine pericardium in 19 patients, porcine pericardium in 20 patients as a patch. Rigit patches in particular such as grafts can cause stenosis by pushing the proximal and distal aorta.

All of our patients had tubular arch hypoplasia in this study, which was calculated to be a risk factor for recoarctation by Dodge-Khatami and colleagues in a 40-year review of patients undergoing coarctation repair ${ }^{11}$. Similarly, Bernabei and colleagues presented a higher incidence of restenosis rate with neonatal arch hypoplasia as compared with arch interruption or the hypoplastic left heart syndrome ${ }^{7}$. Interestingly, all patients in that study underwent arch reconstruction with autologous pericardium. One- and threeyear freedom from recoarctation was 93 and $69 \%$, respectively, and the authors concluded that the use of autologous pericardium in aortic arch reconstruction procedures is valid and associated with an acceptable incidence of recurrent arch obstruction ${ }^{7}$. In our study, $10(20.8 \%)$ patients required reintervention due to distal recoarctation, seven of them treated with successful aortic balloon angioplasty, but 3 required surgical reintervention. We performed resurgery via left thoracotomy in 3 patients using bovine or porcine pericardium. We observed only one $(2 \%)$ proximal restenosis, probably due to the particular shape of the aortic arch, and we performed reoperation via median sternotomy. We believe that our low proximal restenosis rate depends on our technique that extends the patch to the middle of the ascending aorta. Furthermore, with the use of patch enlargement, we did not observe bronchi or trachea compression described as a possible complication of end-to-end anastomosis ${ }^{12}$.

The arch hypoplasia, interruption, or coarctation is efficiently dealt with at the time of the ASO while working through a median sternotomy. It is generally possible to perform a direct

anastomosis for interruption or coarctation with mild tension on the anastomosis. On the other hand, the aortic arch hypoplasia requires an additional longitudinal patch-plasty. This has the advantage of enlarging the size of the ascending aorta, thus facilitating a tension-free neoaortic anastomosis; it achieves an aortic arch of adequate size. Huber et al. conducted a study on 22 patients who underwent ASO and arch repair with 18,1\% overall mortality, and 3 patients required ECMO. Sixteen of 22 patients had arch hypoplasia, and remaining patients had coarctation or IAA, and Huber et al. reported a $44 \%$ rate of arch reintervention ${ }^{13}$. Vouhe"s group described a $76 \%$ actuarial survival rate in 38 patients who underwent ASO with arch repair, mentioning arch reinterventions in three patients $(7.8 \%)^{14}$. By contrast, Planche"s group conducted a study on 67 patients who underwent one-stage repair with either end-to-end (35 patients) or patch enlargement of (32 patients) for AAO relive. Overall, actuarial survival in this series was $94 \%$ in the 32 patients and $75 \%$ 
in the 35 patients over 10 years, and re-interventions required in 15 patients $(22 \%)$ for recoarctation ${ }^{15}$. In our cohort, 11 patients underwent ASO and arch repair with $18.8 \%$ overall mortality; one of them required ECMO, two patients died due to sepsis on the postoperative course, and only one patient (11\%) required reintervention for recoarctation during the follow-up. Our mortality and reintervention rates were similar to the literature for this complicated group. We considered that the one-stage-repair of transposition complex and aortic arch hypoplasia showed good survival results for these highly complex congenital anomalies in high-volume hospitals.

More complex pathologies or functional single ventricle with arch hypoplasia showed high morbidity or mortality rates ${ }^{16}$. Historic outcomes of $\mathrm{PAB}+\mathrm{COA}$ repair have been unfavorable and associated with high hospital death, reduced progression toward subsequent palliative stages, and overall low survival ${ }^{17,18}$. Franklin and colleagues found that

survival after PAB + COA repair was $44 \%$ at 1 year and $22 \%$ at 5 years, and in another study, they found that Fontan candidacy was only $8 \%^{17,18}$. In our study, in Group 1 (PAB + arch repair), mortality rate was $34.8 \%(8 / 27)$, and $62,5 \%(5 / 8)$ of them had functional single ventricle. On the other hand, Poirier et al. conducted a study on 37 children who had arch hypoplasia and biventricular hearts, and they reported no postoperative deaths with isolated aortic arch hypoplasia patients. However, the operative mortality for their total cohort of patients was $13.5 \%^{19}$. Karl and associates have reported similar results of the combined arch and intra-cardiac repair with a $13 \%$ operative mortality rate in a group of 15 infants who underwent a single-stage repair ${ }^{20}$. These mortality rates were similar to our single-stage repair group, with a mortality rate of $10.8 \%$. In our study, only 6 cases with biventricular heart underwent isolated arch reconstruction with no operative mortality. Although the duration of cardiopulmonary bypass time and cross clamp time were significantly higher in the single-stage repair group, postoperative mortality, delayed sternal closure time, VAC treatment usage rate, sudden cardiac arrest rate, and postoperative low cardiac output rates were significantly higher in the palliation group. In our perspective, these results shows the importance of single stage total repair, and the adverse effect of the pallation to the outcomes.

In neonates and some infants, low cardiac output can persist after coarctation repair due to

preoperative LV dysfunction ${ }^{21}$. Lim et al. conducted a study on 69 neonates or infants who underwent single-stage total repair of the aortic arch anomaly using regional perfusion. They reported only four patients $(5.7 \%)$ had postoperative low cardiac output syndrome, and all of them had poor preoperative conditions ${ }^{21}$. In our study, 8 patients $(13.3 \%)$ had postoperative low cardiac output syndrome, and this was significantly higher in our palliation group $(\mathrm{p}=0.022)$. Among 8 patients, 7 require mechanical ventilatory support, and 3 of them had poor ventricular function requiring inotropic in the preoperative period. Only one patient did not need any support preoperatively, but he was also premature.

We only used a direct cannulation method through the innominate artery, even in the small neonates, instead of using a polytetrafluoroethylene graft. We considered it a basic and applicable method which did not conceal the surgical area. Moreover, there was no cannulation-related complication, such as stenosis or intimal injury in our cohort. Usually, the size of the innominate artery was adequate for cannulation, and we easily advanced the $8 \mathrm{Fr}$ arterial cannula. We used ACP perfusion during the repair of aortic arch hypoplasia with a flow rate of $40-50 \mathrm{ml} / \mathrm{kg} / \mathrm{min}$ in order to maintain a perfusion pressure of $50-60 \mathrm{mmHg}$, and all patients were monitored by near-infrared spectroscopy (NIRS). In our series, early postoperative minor neurologic complications as seizures occurred in three patients (5\%), which is better than the reported rates $(4-25 \%)$ in total circulatory arrest groups ${ }^{22}$. Any abnormality was not detected in these patients on CT and electroencephalogram, and fortunately, all patients recovered entirely by anti-epileptic therapy, but the long-term complications such as neuro-developmental abnormalities need to be evaluated further.

Some reports suggested that the higher hematocrit level would be beneficial on neurologic outcomes after the TCA or low flow bypass ${ }^{23}$. But there was some controversy on the optimal hematocrit level, and there has been no gold standard. In our cohort, we maintained a hematocrit level at around $30 \%$, and we believe that this is one of the reasons for not seeing a major neurological complication. 
Pigula et al. reported that the somatic perfusion through various collaterals was maintained during low flow regional perfusion with a flow rate of $30-40 \mathrm{ml} / \mathrm{kg}$ per min and suggested that the support of the subdiaphragmatic viscera should improve the ability of neonates to survive the postoperative period ${ }^{24}$. Lim et al. conducted a study on 48 neonates who underwent aortic arch reconstruction operation using regional perfusion without circulatory arrest. Their mean radial artery perfusion pressure was about $40-50 \mathrm{mmHg}$, the mean duration of regional perfusion time was 33+-16 min, and renal insufficiency occurred in only $4.2 \%$ $(2 / 48)$ of patients in the postoperative course ${ }^{16}$. In our cohort, the mean radial artery perfusion pressure was about 50-60 $\mathrm{mmHg}$, the mean duration of antegrade cerebral perfusion time was $22.4+-7.4 \mathrm{~min}$, and renal insufficiency occurred in only $5 \%(3 / 60)$ of patients in the early postoperative period. On the other hand, Kreuzer et al. and Hammel et al. reported that 1,7\% and 5\% of postoperative acute renal failure rate, respectively, with double arterial cannulation, and they reported lower adverse events were observed by additional descending aorta cannulation ${ }^{25,26}$. We believe that the direct comparison of the results for renal complications was inappropriate because of the various preoperative conditions, but we considered that such a high flow rate would be beneficial in the functional recovery of somatic organs besides cerebral protection.

The retrospective and single-center study design aspects are the main limitation of this study. Studies with multiple centers, including various types of congenital heart disease and long-term outcomes, are needed to demonstrate the surgical results of aortic arch hypoplasia.

In conclusion, aortic arch reconstruction for tubular arch hypoplasia in neonates and infants with or without associated intracardiac lesions can be repaired by single-stage repair with acceptable early and mid-term results. On the other hand, palliation with arch repair should be considered in biventricular neonates with significant preoperative comorbid conditions, and in single ventricle neonates.

\section{Acknowledgements}

None

\section{Financial support}

This research received no specific grant from any funding agency in commercial or not-for-profit sectors.

\section{Conflict of interest}

The authors declare no conflicts of interest concerning the authorship or publication of this article.

\section{Ethical standards}

The authors assert that all procedures contributing to this work comply with the ethical standards of the relevant national guidelines on human experimentation and with the Helsinki Declaration of 1975, as revised in 2008, and has been approved by the institutional committees (ATADEK ethics commitee approval Ndeg :2020-2/6). The authors assert that all procedures contributing to this work comply with the ethical standards of the relevant national guides on the care and has been approved by the institutional committee (ATADEK ethics committee approval Ndeg :2020-2/6).

\section{References}

1. Brown JW, Rodefeld MD, Ruzmetov M. Transverse Aortic Arch Obstruction: When to Go from the Front. Semin Thorac Cardiovasc Surg Pediatr Card Surg Ann 2009; 12:66-69.

2. Planche C, Serraf A, Comas JV, Lacour-Gayet F, Bruniaux J, Touchot A. Anatomic repair of transposition of the great arteries with ventricular septal defect and aortic arch obstruction. J Thorac Cardiovasc Surg 1993; 105:925-33.

3. Gillett C, Wong A, Wilson DG, Wolf AR, Martin RP, Kenny D. Underrecognition of elevated blood pressure readings in children after early repair of coarctation of the aorta. Pediatr Cardiol 2011; $32: 202-5$.

4. Brown ML, Burkhart HM, Connolly HM, et al. coarctation of the aorta: lifelong surveillance is mandatory following surgical repair. J Am Coll Cardiol 2013; 62:1020-5. 
5. Erek E, Aydin S, Suzan D, Yildiz O, Demir IH, Odemis E. Early degeneration of extracellular matrix used for aortic reconstruction during Norwood operation. Ann Thorac Surg (2016) 101:758-60.

6. Mery CM, Khan MS, Guzman-Prineda FA, Verm R, Umakanthan R, Watrin CH et al. Contemporary results of surgical repair of recurrent aortic arch obstruction. Ann Thorac Surg. (2014) 98:133-40.

7. Bernabei M, Margaryan R, Arcieri L, Bianchi G, Pak V, Murzi B.Aortic arch reconstruction in newborns with an autologous pericardial patch: contemporary results. Interact Cardiovasc Thorac Surg 2013;16(3):282-285.

8. Roussin R, Belli E, Lacour-Gayet F, et al. Aortic arch reconstruction with pulmonary autograft patch aortoplasty. J Thorac Cardiovasc Surg 2002;123(3):443-448, discussion 449-450.

9. Morales DL, Scully PT, Braud BE, et al. Interrupted aortic arch repair: aortic arch advancement without a patch minimizes arch reinterventions. Ann Thorac Surg 2006;82(5):1577-1583, discussion $1583-1584$.

10. Gaynor JW. Management strategies for infants with coarctation and an associated ventricular septal defect. J Thorac Cardiovasc Surg 2001;122(3):424-426

11. Dodge-Khatami A, Backer CL, Mavroudis C. Risk factors for recoarctation and results of reoperation: a 40-year review. J Card Surg 2000;15(6):369-377.

12. Jhang WK, Park J, Seo D, Goo HW, Gwak M. Perioperative evaluation of airways in patients with arch obstruction and intracardiac defects. Ann Thorac Surg 2008; 85:1753-8.

13. Huber C, Mimic B, Oswal N, Sullivan I, Kostolny M, Elliott M et al. Outcomes and re-interventions after one-stage repair of transposition of great arteries and aortic arch obstruction. European Journal of Cardio-thoracic Surgery 2011; 39: 213-221.

14. Pocar M, Villa E, Degandt A, Mauriat P, Pouard P, Vouhe' PR. Long-term results after primary one-stage repair of transposition of the great arteries and aortic arch obstruction. J Am Coll Cardiol 2005;46(7): 1331-8.

15. Mohammadi S, Serraf A, Belli E, Aupecle B, Capderou A, Lacour-Gayet F, Martinovic I, Piot D, Touchot A, Losay J, Planche' C. Left-sided lesions after anatomic repair of transposition of the great arteries, ventricular septal defect, and coarctation: surgical factors. J Thorac Cardiovasc Surg 2004;128(1):44-52.

16. Lim C, Kim WH, Kim SC, Rhyu JW, Baek MJ, Oh SS et al. Aortic arch reconstruction using regional perfusion without circulatory arrest. European Journal of Cardio-thoracic Surgery 2003; 23:149-155.

17. Franklin RC, Spiegelhalter DJ, Anderson RH, et al. Double inlet ventricle presenting in infancy II. Results of palliative intervention. J Thorac Cardiovasc Surg 1991; 101:917-23.

18. Franklin RC, Spiegelhalter DJ, Rossi Filho RI, et al. Doubleinlet ventricle presenting in infancy III. Outcome and potential for definitive repair. J Thorac Cardiovasc Surg 1991; 101:924-34.

19. Poirier NC, Van Arsdell GS, Brindle M, Thyagarajan GK, Coles JG, Black MD et al. Surgical Treatment of Aortic Arch Hypoplasia in Infants and Children with Biventricular Hearts. Ann Thorac Surg 1999; 68:2293-7

20. Karl TR, Sano S, Brawn W, Mee RB. Repair of hypoplastic or interrupted aortic arch via sternotomy. J Thorac Cardiovasc Surg 1992; 104:688-95.

21. Lim HK, Kim WH, Jang WS, Lim C, Kwak JG, Lee C et al. One-stage total repair of aortic arch anomaly using regional perfusion. European Journal of Cardio-thoracic Surgery 2007;31: 242-248.

22. Hickey PR. Neurologic sequelae associated with deep hypothermic circulatory arrest. Ann Thorac Surg 1998; 65:65-70.

23. Sakamoto T, Zurakowski D, Duebener LF, Hatsuoka S, Lidov HGW, Holmes GL et al. Combination of alpha-stat strategy and hemodilution exacerbates neurologic injury in a survival piglet model with deep hypothermic circulatory arrest. Ann Thorac Surg 2002; 73:180-190.

24. Pigula FA, Gandhi SK, Siewers RD, Davis PJ, Webber SA, Nemoto EM. Regional low-flow perfusion provides somatic circulatory support during neonatal aortic arch surgery. Ann Thorac Surg 2001; 72:401-406.

25. Kreuzer M, Sames-Dolzer E, Schausberger L, Tulzer A, Ratschiller T, Haizinger B et al. Doublearterial cannulation: a strategy for whole body perfusion during aortic arch reconstruction. Interactive 
CardioVascular and Thoracic Surgery (2018) 1-7

26. Hammel JM, Deptula JJ, Karamlou T, Wedemeyer E, Abdullah I, Duncan KF. Newborn aortic arch reconstruction with descending aortic cannulation improves postoperative renal function. Ann Thorac Surg 2013;96: 1721-6.

\section{Figure Legends}

Figure 1 . Postoperative CT scan at the $6^{\text {th }}$ month with a 3 -D reconstruction of a neonate who underwent arterial switch and aortic arch reconstruction operation because of Taussig Bing anomaly with AAH viewed laterally (A, B). DA, descending aorta

Figure 2 . Kaplan-Meier survival for both groups undergoing aortic arch repair with $95 \%$ CI at follow up.

Figure 3. Angiographic images of two patients with postoperative recoarctation (A, B).

Figure 4 . Kaplan-Meier curve showing the freedom from arch reintervention for both groups.

\section{Hosted file}

arcus table 1.pdf available at https://authorea.com/users/320168/articles/484867-managementof-aortic-arch-hypoplasia-in-neonate-and-infants

\section{Hosted file}

Arcus Table 2.pdf available at https://authorea.com/users/320168/articles/484867-managementof-aortic-arch-hypoplasia-in-neonate-and-infants

\section{Hosted file}

Arcus Table 3.pdf available at https://authorea.com/users/320168/articles/484867-managementof-aortic-arch-hypoplasia-in-neonate-and-infants

\section{Hosted file}

Arkus Table 4.pdf available at https://authorea.com/users/320168/articles/484867-managementof-aortic-arch-hypoplasia-in-neonate-and-infants

\section{Hosted file}

Arcus Table 5.pdf available at https://authorea.com/users/320168/articles/484867-managementof-aortic-arch-hypoplasia-in-neonate-and-infants

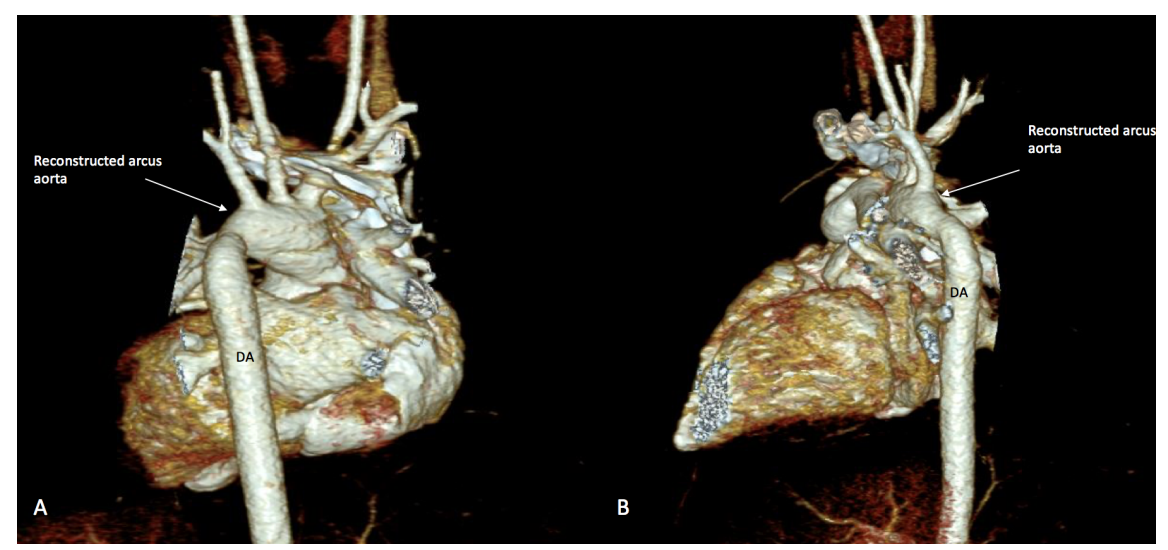






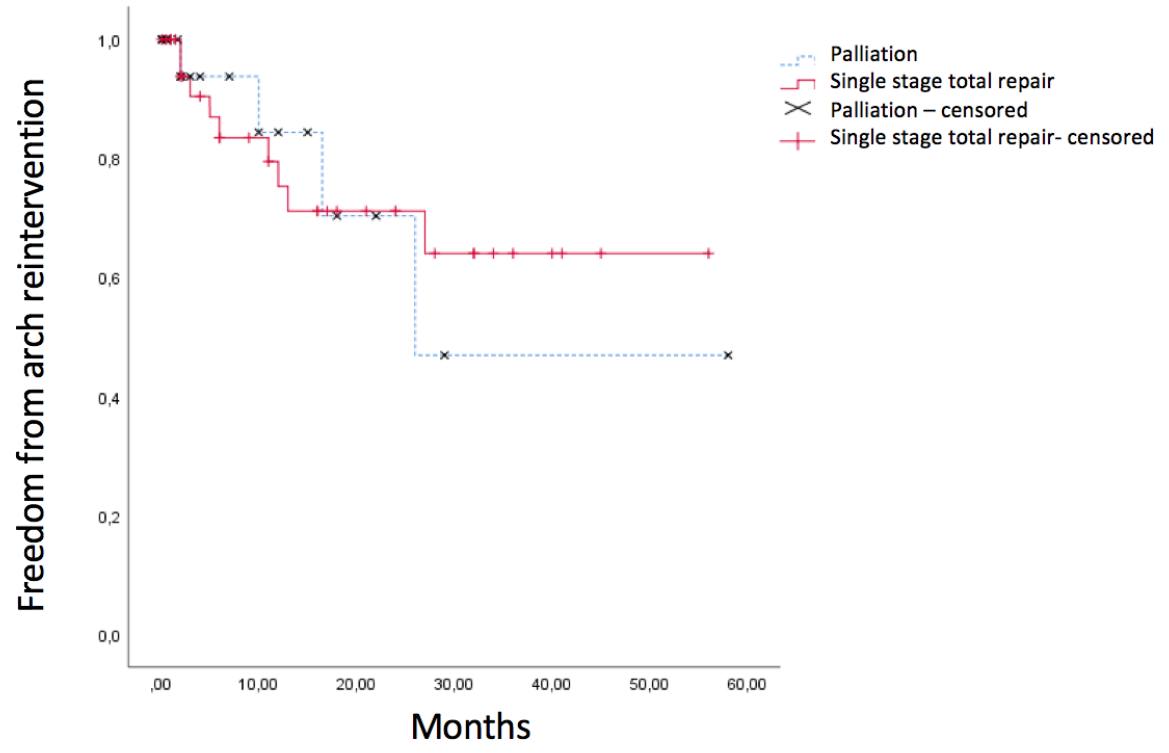

